\title{
Üniversite Öğrencilerinde Sosyal Fizik Kaygısı ve Depresyonun Yeme Bozukluğu Riski ile İlişkisi
}

\author{
Relationship between Social Physique Anxiety, Depression and the Risk of Eating Disorders in \\ University Students
}

\section{Fatma Tayhan Kartal' ${ }^{1}$, Memnune Kabakuş Aykut ${ }^{2}$}

Geliş tarihi/Received: 26.06.2019 • Kabul tarihi/Accepted: 08.08.2019

\section{ÖZET}

Amaç: Üniversite öğrencileri yeme bozuklukları açısından risk altında olan gruplardan biridir. Bu çalışma üniversite öğrencilerinde sosyal fizik kaygı ve depresyonun yeme bozuklukları ile ilişkisini araştırmak amacıyla yapılmıştır.

Bireyler ve Yöntem: Yaş ortalaması 20.6ะ1.7 yıl olan 318 öğrenci üzerinde yapılan bu çalışmada yeme davranış bozukluğu riskini saptamak için Yeme Tutum Testi (EAT-26) ve REZZY (SCOFF) Yeme Bozuklukları Ölçeği, depresyon varlığını saptamak için Beck Depresyon Ölçeği (BDÖ), bireylerin fiziksel görünüşlerinin başkaları tarafından değerlendirildiğinde hissettikleri rahatsızlık düzeyini ölçmede ise Sosyal Fizik Kaygı̈ Ölçeği kullanılmıştır.

Bulgular: EAT-26 ve REZZY ölçeklerine göre öğrencilerin sırasıyla \%20.1'inin ve \%28.6'sının yeme bozukluğu riski altında olduğu belirlenmiştir. Yeme davranış bozukluğu riski sosyal fizik kaygı $(r=0.345, p=0.000)$ ve depresyon düzeyi $(r=0.247$, $\mathrm{p}=0.000$ ) ile anlamlı olarak ilişkilidir. Yeme davranış bozukluğu riski ve beden kütle indeksi arasında anlamlı, pozitif bir ilişki saptanmıştır ( $\mathrm{r}=0.248, \mathrm{p}=0.000)$. Ayrıca hafif şişman ve obez kız öğrencilerde sosyal fizik kaygı düzeyinin daha yüksek olduğu bulunmuştur $(\mathrm{p}<0.05)$.

Sonuç: Üniversite öğrencilerinde sosyal fizik kaygı ve depresyonun, öğrencilerin yeme bozukluğu riskiyle karşı karşıya kalmalarına neden olabileceği görülmüştür. Bu durum dikkate alınarak yeme bozuklukları ve neden olan faktörlere yönelik daha büyük örneklemde çalışmalar yapılmasına ihtiyaç vardır. Riskli gruplarda (cinsiyet olarak kız, hafif şişmanobez, depresyon varlığı vb.) kısa ölçeklerin (REZZY vb.) uygulanması ve vücut ağırlığının izlemi ile düzensiz yeme şekilleri değerlendirilerek, olası bir depresyon ve beraberinde gelişebilecek olası bir yeme bozukluğunun önüne geçilebilir.

Anahtar kelimeler: Depresyon, sosyal fiziki kaygı, yeme bozuklukları

1. İletişim/Correspondence: Gümüşhane Üniversitesi, Sağlık Bilimleri Fakültesi, Beslenme ve Diyetetik Bölümü, Gümüşhane, Türkiye

E-posta: fatma_tayhan@hotmail.com • https://orcid.org/0000-0001-8524-9048
2. Gümüşhane Üniversitesi, Sağllk Bilimleri Fakültesi, Beslenme ve Diyetetik Bölümü, Gümüşhane, Türkiye

은ttps://orcid.org/0000-0002-8023-4282 


\section{ABSTRACT}

Aim: University students are one of the groups who are at risk for eating disorders. This study was conducted to investigate the relationship between social physique anxiety and depression with the risk of eating disorders in university students.

Subjects and Method: Eating Attitude Test (EAT-26) and REZZY (SCOFF) Eating Disorders Scale were used to assess the risk of eating behaviour disorder in a total of 318 students with a mean age of 20.6 \pm 1.7 years. Beck Depression Scale (BDS) was used to determine the presence of depression, and Social Physique Anxiety Scale was used to measure the level of discomfort that individuals feel when their physical appearance is evaluated by others.

Results: According to EAT-26 and REZZY scales, $20.1 \%$ and $28.6 \%$ of students were at risk of eating disorders, respectively. The risk of eating disorders was significantly associated with social physique anxiety $(\mathrm{r}=0.345, \mathrm{p}=0.000)$ and depression $(r=0.247, p=0.000)$. There was also a significant positive association between risk of eating disorders and body mass index $(r=0.248, p=0.000$. Additionally, social physique anxiety levels were higher in overweight and obese girls $(p<0.05)$.

Conclusion: Social-physical anxiety and depression may lead to eating disorder in university students. Further studies on risk of eating disorders and underlying factors are needed to confirm these findings on large samples. The development of depression and subsequent risk of eating disorders can be prevented by assessment of disordered eating behaviors in 'at risk' groups (e.g. females, overweight and/or obese subjects, presence of depression, etc.) by using short screening tools (e.g. REZZY) and monitoring body weight.

Keywords: Depression, social physique anxiety, eating disorders

\section{GíRiş}

Genç yetişkinler toplumsal baskı, düşük öz saygı ve ideal vücut boyutu ile ilgili gerçekçi olmayan algılamalar için daha büyük bir risk altındadır (1). $\mathrm{Bu}$ dönemde yaşanan beden memnuniyetsizliği, vücut ağırlık kaybı için diyetsel kısıtlamalara ve yeme bozukluklarına yol açmaktadır (2). Yeme bozuklukları sadece maruz kalanlarda değil aynı zamanda bu kişilerin ailelerinde de çok büyük sıkıntılara neden olan, besin tüketimi ve beden imajı ile ilişkilendirilmiş, izlemi ve tedavisi oldukça zor ruhsal bozukluklardır (3). Genel anlamda genetik, sosyokültürel ve psikolojik faktörlerin yeme bozukluklarına sebep olduğu düşünülmektedir (4). Ayrıca toplumdaki 'zayıf olan güzeldir' inanışı nedeniyle güzellik algısındaki değişim ve medyadaki 'sıfır beden' algısı adölesan ve genç erişkin çağı üzerinde baskı kurmakta, onları bilinçsizce diyet yapmaya teşvik etmekte ve beraberinde yeme bozukluklarına neden olmaktadır (5). Kadınlarda daha sık görülmekle birlikte, yeme bozuklukları yalnızca kadınlara özgü bir hastalık değildir ve her iki cinsiyette de karşılaşılmaktadır (6). Bununla birlikte yeme bozukluğu olanların, yeme bozukluğu olmayanlara göre obez olma ihtimalinin 3-6 kat daha fazla olduğu tahmin edilmektedir (7).

Görülme sıklığı ve risk faktörlerine bakılarak yeme bozukluğu gelişme riskinin yüksek olduğu bazı dönemler belirlenmiştir. Bu riskli dönemlerden biri hiç şüphesiz üniversite dönemidir (8). Üniversite dönemi, beslenme alışkanlıkları da dâhil olmak üzere yaşam tarzı değişiklikleri ile önemli bir yere sahiptir. Bu dönemde aileden ve alışılmış kültürden ayrılan bireylere ekonomik, sosyal ve akademik sorumluluklar yüklenmektedir. Özellikle uyum sorunu yaşayan gençlerde yalnızlık hissi, grup içinde uyuşmazlıklar, uyku ve yeme bozuklukları ortaya çıkmaktadır (9). Sıklıkla yeme bozukluklarına eşlik eden depresyon ise gençlerin akademik performansını düşürmekte, önlem alınmazsa sosyal kaygı bozukluğuna ve uyum sağlama ile ilgili farklı problemlere neden olabilmektedir (10).

Sosyal fizik kaygı durumu, başkalarının kendini fizikselgörünüm açısından değerlendirdiğindebireyin yaşadığı gerginlik ve kaygı olarak tanımlanabilir. 
Sosyal fizik kaygının temel olumsuzlukları beden memnuniyetsizliği, yeme davranış bozuklukları, depresyon, vücut ağırlığı, vücut şekli ve yeme ile ilgili kaygılardır (11). Yeme bozuklukları olan kişilerde dış görünümle ilgili olan sosyal kaygılar yaygındır. Sosyal kaygı semptomları ile çeşitli yeme bozukluğu indeksleri arasında güçlü bir ilişki olduğu belirtilmektedir (12). Bu nedenle, genç erişkinlerde sosyal görünüm kaygısının gelecekteki yaşamları üzerinde olumsuz etkileri olabilmektedir (13).

Üniversite döneminde yeni bir ortama uyum sağlama, tek başına geçimini sağlama, sosyal çevre tarafından kabul görme, akademik yaşamın talepleri ve yaklaşmakta olan mesleki yaşamın belirsizliği, stres, depresyon ve kaygı ile sonuçlanan önemli birçok duygusal yükü beraberinde getirmektedir (14). $\mathrm{Bu}$ dönemde maruz kalınan stres yapıcı faktörlerin fazla olması ve gençlerin başa çıkma stratejileri hakkında bilgi sahibi olmayışları nedeniyle kendine uygun bir zemin hazırlayan yeme bozukluklarl, üniversite kampüslerinde yaygınlaşmakta ve tedavi edilmediği takdirde önemli fiziksel, psikolojik, sosyal ve akademik sorunlara yol açabilmektedir (15). Üniversite öğrencileri üzerinde yapılan epidemiyolojik çalışmalarda da yeme bozukluğu görülme riskinin yüksek olduğu, bu durumun ise stres ve depresyon ile yakından ilişkili olduğu tespit edilmiştir $(9,16)$. Bu dönem ile ilgili yapllacak çalışmalar ortaya çıkabilecek sorunların önlenmesine katkı sağlayacaktır. $\mathrm{Bu}$ çalışmada, üniversite öğrencilerinin sosyal fizik kaygllarının ve depresyon durumlarının yeme bozuklukları ile ilişkisinin araştırılması amaçlanmıştır.

\section{BİREYLER VE YÖNTEM}

\section{Örneklem Seçimi}

$\mathrm{Bu}$ çalışma 2018-2019 eğitim-öğretim yllında Gümüşhane Üniversitesi Sağlık Bilimleri Fakültesi’nin çeşitli bölümlerinde okuyan 18 yaş ve üzeri 318 gönüllü öğrenci üzerinde yapılmıştır. Kronik hastalığı olan ve iştahı etkileyen ilaç kullanan (antidepresan, metformin vb.) bireyler çalışmaya dahil edilmemiştir. Çalışmanın evrenini oluşturan 1,598 öğrenci içinden hesaplanan güç analiziyöntemiileörneklem sayısı \%95 güven aralığında 318 olarak belirlenmiştir. Çalışma için Gümüşhane Üniversitesi Etik Komisyonu'ndan 2019-5 sayll ve 08.05.2019 tarihli 'Etik Komisyon Onayı' alınmıştır. Çalışma öncesi tüm katılımcılar 'Gönüllü Onam Formu’nu okuyup, imzalamıştır.

\section{Araştırmanın Genel Planı ve Verilerin Toplanması}

Çalışma verileri yüz yüze görüşme tekniği kullanılarak araştırmacı tarafından uygulanan bir anket formu ile toplanmıştır. Anket formu, bireylerin genel ve sağlık bilgilerini, beslenme alışkanlıklarını, sosyal fizik kaygısı (Sosyal Fiziki Kaygı Ölçeği) ve depresyon düzeyleri (Beck Depresyon Ölçeği) ile yeme bozukluğu riskini [Yeme Tutum Testi 26 (EAT-26) ve REZZY yeme bozuklukları ölçeği ile] belirlemeye yönelik sorulardan oluşmaktadır. Yeme bozukluklarını değerlendirmede kullanılan ölçeklerden biri olan REZZY, hem kısa olması sonucu kolay uygulanabilmesi hem de güvenilirliğinin yüksek olması nedeniyle yapılan bu çalışmada ağırlıklı olarak yer almıştır. Ayrıca araştırmacı tarafından yöntemine uygun olarak antropometrik ölçümler (boy uzunluğu, vücut ağırlığı) alınmıştır. Öğrencilerin vücut ağırlığı aç karnına, ince kıyafetle ve ayakkabısız olarak 0.1 kg duyarlılığa sahip boy ölçerli dijital tartı kullanılarak ölçülmüştür. Boy uzunluğu ölçümü için ayakların yan yana ve başın Frankfort düzlemde olmasına dikkat edilmiştir. Ayrıca katılımcıların vücut ağırlığının, boy uzunluğunun metre karesine bölünmesi (vücut ağırlığı /boy uzunluğu $\left[\mathrm{kg} / \mathrm{m}^{2}\right]$ ) ile beden kütle indeksi (BKI) değerleri hesaplanmıştır. Elde edilen değerler zayıf (BKİ: <18.5 kg/m²), normal (BKİ: $18.5-24.99 \mathrm{~kg} /$ $\mathrm{m}^{2}$ ), hafif şişman (BKİ: $25.0-29.99 \mathrm{~kg} / \mathrm{m}^{2}$ ) ve obez (BKİ: $\geq 30.0 \mathrm{~kg} / \mathrm{m}^{2}$ ) şeklinde sinıflandırılmıştır (6).

Yeme Tutum Testi (EAT-26): Hem klinik hem de gözlemsel çalışmalarda yeme bozuklukları riskini belirlemede kullanılan ve 26 maddeden oluşan Yeme Tutum Testi, ilk olarak Garner ve Garfinkel (17) tarafından geliştirilmiştir. Türkçe geçerlilik ve 
güvenilirliği Savaşır ve Erol (18) tarafından yapılan ölçeğin Cronbach alfa güvenirlilik katsayısı 0.70 olarak bulunmuştur. EAT-26 puanının artması yeme tutumu bozukluğunun arttığının göstergesi olup toplam skorun $\geq 20$ olması bireylerin yeme bozukluğuna sahip olduğunu göstermektedir. Ölçek puanlaması 0 ile 78 arasında değişmektedir (18).

Sosyal Fizik Kaygı Ölçeği (SFKÖ): 12 madde ve iki alt ölçekten oluşan bu ölçek, Hart et al. (19) tarafindan geliştirilmiştir. Türkçe geçerlilik ve güvenilirliği yapılan ölçeğin Cronbach alfa güvenirlilik katsayısı 0.80 olarak bulunmuştur (20). Ölçekten alınan en düşük puan 12, en yüksek puan 60'dır. Alınan puanlar arttıkça kişinin kendi görünüşünden duyduğu kaygı da artmaktadır. Ölçek, bireylerin fiziksel görünüşlerinin başkaları tarafindan gözlemlendikleri veya değerlendirildiklerinde hissettikleri rahatsızlık düzeyi ile ilgili sorular içermektedir (20).

Beck Depresyon Ölçeği (BDÖ): Duygusal, bilişsel, somatik ve motivasyonel bileşenleri ölçmek amacıyla Beck (21) tarafından geliştirilen ölçeğin Türkçe geçerlilik ve güvenilirliği Hisli (22) tarafından yapılmış ve Cronbach alfa güvenirlilik katsayısı 0.80 olarak bulunmuştur. Temel amacı depresyon belirtilerini kapsamlı bir biçimde değerlendirmek olan ölçek 21 maddeden oluşmaktadır. Sorulara 0-3 arası puan verilerek, 0-63 arasında değişen skorlar elde edilen ölçekte, kesme puanı 17 ve üzeridir (22).

REZZY (SCOFF) Yeme Bozuklukları Ölçeği: Yeme bozukluğu riskini tarayarak daha ileri inceleme ve araştırma için olanak sağlayan bu ölçek, Hill et al. (23) tarafından her bir sorudan seçilen harfler birleştirilerek 'SCOFF' adıyla geliştirilmiştir. Türkçe geçerlilik ve güvenilirliği Aydemir ve ark. (24) tarafından yapıldıktan sonra araştırmacılar tarafından seçilen harflerle adı REZZY olarak belirlenmiştir. Toplam 5 maddeden oluşan ve her maddeye 1 puan verilen ölçekte, 2 ve üzeri puan alan birey yeme bozukluğu açısından risk altında kabul edilmektedir (24). Yapılan bir çalışmada daha önce belirlenememiş yeme bozukluğu vakalarının \%81'ini ayırt edebildiği görülen ölçeğin Cronbach alfa iç tutarlılık katsayısı 0.74 olarak belirtilmiştir (25).

\section{Verilerin İstatistiksel Değerlendirmesi}

Araştırmadan elde edilen veriler bilgisayar ortamında SPSS for version 23.0 (Statistical Package for Social Sciences, Chicago, IL, USA) adl paket programında analiz edilmiştir. Sürekli sayısal veriler ortalama ve standart sapma ( $\left.\overline{\mathrm{X}}_{ \pm} \mathrm{SS}\right)$, kesikli veriler sayı (S) ve yüzde (\%) olarak verilmiştir. Normal dağılım gösteren veriler arasındaki ilişki Pearson korelasyon analiziyle, normal dağllıma uymayan veriler ise Spearman korelasyon analizi kullanılarak test edilmiştir. İki nitel değişkenin birbiriyle olan ilişkisinin incelenmesinde Pearson kikare testi kullanılmıştır. İki grup arasındaki farklar Student-t testi ile değerlendirilmiştir. İstatistiksel anlamlılık $\mathrm{p}<0.05$ olarak kabul edilmiştir.

\section{BULGULAR}

Öğrencilerin \%31.1’i erkek, \%68.9'u kızdır. Çalışmaya katılan öğrencilerin \%23.3'ü sigara, \%8.5'i ise alkol kullanmaktadır. Yaklaşık \%80'i öğün atlamaktadır ve en çok atlanan öğün öğle öğünüdür (\%65.0). Öğrencilerin \%63.8’i yurtta, \%34.3’ü öğrenci evinde kalmaktadır. Kız ve erkek öğrencilerin \%13.5'i hafif şişman veya obezdir. Öğrencilerin \%20.1'inin EAT26 puanı 20 ve üzerinde, \%28.6'sının REZZY puanı 2 ve üzerinde, \%28'inin de BECK skoru 17 ve üzerinde bulunmuştur (Tablo 1).

Tablo 2'de yeme bozukluğu, depresyon durumu ve sosyal fizik kaygının cinsiyete göre karşılaştırılması verilmiştir. Buna göre kız öğrencilerin sosyal fizik kaygı puanlarının ve REZZY skorlarının erkeklere göre anlamlı olarak daha yüksek olduğu bulunmuştur $(\mathrm{p}<0.05)$. Ancak, EAT-26 ölçeğinden alınan puanların ortalamaları cinsiyete göre farklı bulunmamıştır (p>0.05). EAT-26'ya göre erkek öğrencilerin \%21.2'si, kız öğrencilerin de \%19.6'sı, REZZY'ye göre ise erkeklerin \%22.2'si, kızların \%31.5'i yeme bozukluğu riski altındadır ( $p>0.05)$. 
Tablo 1. Öğrencilerin genel özelliklerine göre dağılımı ile ortalama BKİ ve yaş değerleri

\begin{tabular}{|c|c|c|}
\hline & $\mathbf{S}$ & $\%$ \\
\hline \multicolumn{3}{|l|}{ Cinsiyet } \\
\hline Erkek & 99 & 31.1 \\
\hline $\mathrm{K} ı \mathrm{Z}$ & 219 & 68.9 \\
\hline \multicolumn{3}{|l|}{ Bölüm } \\
\hline Beslenme & 145 & 45.6 \\
\hline Sosyal Hizmet & 82 & 25.8 \\
\hline İş Sağlığı ve Güvenliği & 91 & 28.6 \\
\hline Sigara kullanan & 74 & 23.3 \\
\hline Alkol kullanan & 27 & 8.5 \\
\hline Öğün atlayan & 257 & 80.8 \\
\hline \multicolumn{3}{|l|}{ Atlanan öğün } \\
\hline Sabah & 88 & 34.2 \\
\hline Öğle & 167 & 65.0 \\
\hline Akşam & 2 & 0.8 \\
\hline \multicolumn{3}{|l|}{ Barınma } \\
\hline Yurt & 203 & 63.8 \\
\hline Öğrenci evi & 109 & 34.3 \\
\hline Aile yanında & 6 & 1.9 \\
\hline EAT-26 <20 & 254 & 79.9 \\
\hline EAT-26 $\geq 20$ & 64 & 20.1 \\
\hline REZZY $\leq 1$ & 227 & 71.4 \\
\hline REZZY $\geq 2$ & 91 & 28.6 \\
\hline BECK $<17$ & 229 & 72.0 \\
\hline BECK $\geq 17$ & 89 & 28.0 \\
\hline Hafif şişman ve obez & 43 & 13.5 \\
\hline Erkek & 18 & 18.2 \\
\hline $\mathrm{K} ı \mathrm{z}$ & 25 & 11.4 \\
\hline BKI, $\mathbf{k g} / \mathbf{m}^{2}$ & \multicolumn{2}{|c|}{$\overline{\mathrm{X}} \pm \mathrm{SS}$} \\
\hline Erkek & \multicolumn{2}{|c|}{$23.0 \pm 3.1$} \\
\hline $\mathrm{K} ı \mathrm{z}$ & \multicolumn{2}{|c|}{$21.2 \pm 2.8$} \\
\hline Yaş, yıl & \multicolumn{2}{|c|}{$20.6 \pm 1.7$} \\
\hline
\end{tabular}

EAT-26: Yeme tutum testi 26, REZZY: REZZY (SCOFF) yeme bozukluklarl ölçeği, BECK: BECK depresyon ölçeği, BKİ: Beden kütle indeksi.

EAT-26 ölçeğinden alınan puanlar sosyal fizik kaygısı, depresyon ve REZZY yeme davranışları ölçeklerinden alınan puanlarla pozitif yönde ilişkili bulunmuştur $(p<0.05)$. REZZY ölçek puanları ise hem sosyal fizik kaygı ve alt boyutlarıyla (fiziksel görünüm rahatlı̆̆ [FGR] ve olumsuz değerlendirilme beklentisi [ODB]) hem de depresyon puanlarıyla pozitif yönde
Tablo 2. Cinsiyete göre ölçek puanlarının ortalama değerleri ve yeme bozukluğu risk durumu

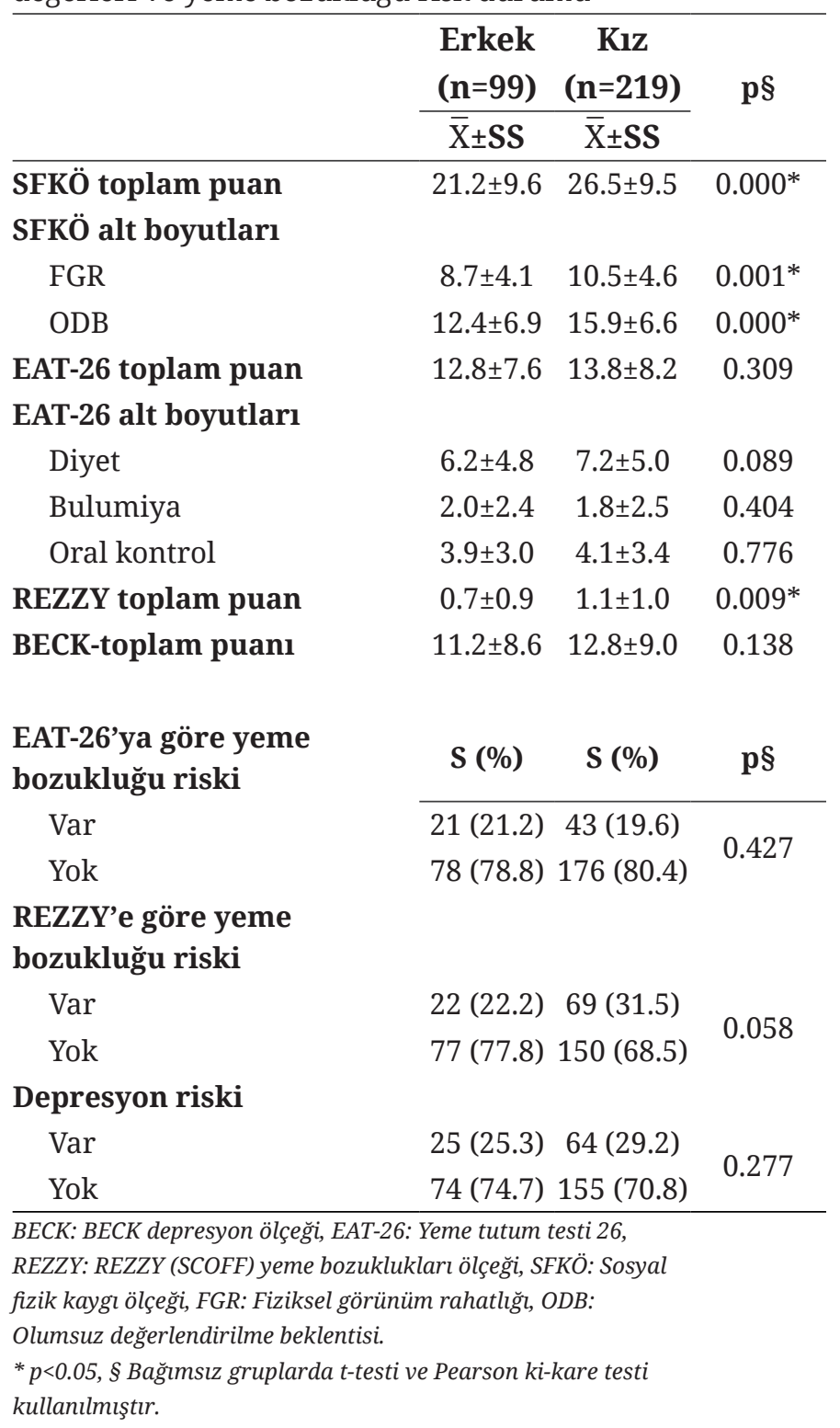

ilişkilidir $(\mathrm{p}<0.05)$. Öğrencilerin BKI’leri ile BECK depresyon ölçeği puanları arasında negatif yönde, REZZY puanları ile pozitif yönde anlamlı bir ilişki saptanmıştır. Ayrıca öğrencilerin sosyal fizik kaygı puanları ile BECK depresyon ölçeği puanları arasında pozitif yönde zayıf bir ilişki vardır ( $r=0.329$, $p=0.000)$ (Tablo 3).

Hafif şişman ve obez kız öğrencilerde sosyal fizik kaygı puanları, olumsuz değerlendirilme beklentisi 
Tablo 3. Ölçek ve ölçek alt boyutlarından alınan puanların birbiriyle ilişkisi

\begin{tabular}{lccccc}
\hline & FGR & ODB & SFKÖ & BECK & REZZY \\
\hline EAT-26 & 0.103 & 0.090 & 0.110 & 0.134 & 0.275 \\
BKİ & $\mathrm{p}=0.068$ & $\mathrm{p}=0.111$ & $\mathrm{p}=0.050^{*}$ & $\mathrm{p}=0.017^{*}$ & $\mathrm{p}=0.000^{*}$ \\
& 0.060 & -0.048 & -0.006 & -0.152 & 0.248 \\
REZZY & $\mathrm{p}=0.294$ & $\mathrm{p}=0.400$ & $\mathrm{p}=0.919$ & $\mathrm{p}=0.007^{*}$ & $\mathrm{p}=0.000^{*}$ \\
& 0.348 & 0.263 & 0.345 & 0.247 & \\
BECK & $\mathrm{p}=0.000^{*}$ & $\mathrm{p}=0.000^{*}$ & $\mathrm{p}=0.000^{*}$ & $\mathrm{p}=0.000^{*}$ & \\
& 0.260 & 0.289 & 0.329 & & \\
\hline
\end{tabular}

FGR: Fiziksel görünüm rahatllğı, ODB: Olumsuz değerlendirilme beklentisi, SFKÖ: Sosyal fizik kaygı ölçeği, BKì: Beden kütle indeksi

${ }^{*} p<0.05$, Pearson korelasyon testi kullanilmıştır.

Tablo 4. Ölçek puanlarının cinsiyete ve beden kütle indeksine (BKİ) göre karşılaştırılması

\begin{tabular}{|c|c|c|c|c|c|c|}
\hline & \multicolumn{2}{|c|}{ Erkek (n=99) } & \multicolumn{4}{|c|}{$\mathrm{K} 1 \mathrm{z}(\mathrm{n}=219)$} \\
\hline & $\begin{array}{c}<25 \mathrm{~kg} / \mathrm{m}^{2} \\
(\mathrm{n}=81)\end{array}$ & $\begin{array}{c}\geq 25 \mathrm{~kg} / \mathrm{m}^{2} \\
\quad(\mathrm{n}=18)\end{array}$ & \multirow{2}{*}{$p \S$} & $\begin{array}{c}<25 \mathrm{~kg} / \mathrm{m}^{2} \\
(\mathrm{n}=194)\end{array}$ & $\begin{array}{c}\geq 25 \mathrm{~kg} / \mathrm{m}^{2} \\
\quad(\mathrm{n}=25)\end{array}$ & \multirow[t]{2}{*}{$p \S$} \\
\hline & $\overline{\mathrm{X}} \pm \mathbf{S S}$ & $\overline{\mathrm{X}} \pm \mathbf{S S}$ & & $\overline{\mathrm{X}} \pm \mathrm{SS}$ & $\overline{\mathrm{X}} \pm \mathrm{SS}$ & \\
\hline SFKÖ toplam puan & $21.7 \pm 9.5$ & $18.8 \pm 10.0$ & 0.231 & $25.7 \pm 9.2$ & $32.4 \pm 10.0$ & $0.005^{*}$ \\
\hline \multicolumn{7}{|l|}{ SFKÖ alt boyutları } \\
\hline ODB & $12.9 \pm 6.8$ & $10.2 \pm 7.0$ & 0.169 & $15.5 \pm 6.5$ & $19.1 \pm 6.3$ & $0.025^{*}$ \\
\hline FGR & $8.7 \pm 4.0$ & $8.5 \pm 4.7$ & 0.594 & $10.2 \pm 4.5$ & $13.4 \pm 4.7$ & $0.004^{*}$ \\
\hline REZZY toplam puan & $0.7 \pm 0.9$ & $1.1 \pm 0.9$ & $0.027^{*}$ & $1.0 \pm 1.0$ & $1.8 \pm 1.0$ & $0.000^{*}$ \\
\hline BECK-toplam puan & $11.7 \pm 8.7$ & $9.2 \pm 7.7$ & 0.302 & $12.8 \pm 9.2$ & $12.8 \pm 7.7$ & 0.677 \\
\hline EAT-26 toplam puan & $13.2 \pm 7.7$ & $11.3 \pm 7.4$ & 0.338 & $13.7 \pm 8.3$ & $15.4 \pm 7.1$ & 0.167 \\
\hline \multicolumn{7}{|l|}{ EAT-26 alt boyutları } \\
\hline Diyet & $6.2 \pm 5.1$ & $6.2 \pm 3.4$ & 0.512 & $6.7 \pm 4.9$ & $11.2 \pm 4.3$ & $0.000^{*}$ \\
\hline Bulumiya & $2.0 \pm 2.3$ & $2.3 \pm 2.8$ & 0.829 & $1.8 \pm 2.5$ & $1.8 \pm 2.7$ & 0.703 \\
\hline Oral Kontrol & $4.3 \pm 3.1$ & $2.5 \pm 2.2$ & $0.025^{*}$ & $4.3 \pm 3.5$ & $1.8 \pm 1.4$ & $0.000^{*}$ \\
\hline
\end{tabular}

FGR: Fiziksel görünüm rahatlğ̆l, ODB: Olumsuz değerlendirilme beklentisi, SFKÖ: Sosyal fizik kaygı ölçeği, BKİ: Beden kütle indeksi

${ }^{*} p<0.05$, §Mann Whitney U Testi kullanilmıştır.

ve fiziksel görünüm rahatlı̆̆ı genel popülasyona (kız) göre daha yüksek bulunmuştur $(\mathrm{p}<0.05)$. REZZY skoru hafif şişman ve obez kız ve erkeklerde yüksek bulunmuştur $(\mathrm{p}<0.05)$ (Tablo 4).

REZZY'e göre yeme davranış bozukluğu riski olan ve olmayan öğrenciler karşılaştırıldığında, BKI’nin (sirasıyla $22.8 \pm 2.9$ ve $21.4 \pm 2.9$ ), depresyon gelişme riskinin (sırasıyla $14.4 \pm 9.0$ ve $11.5 \pm 8.7$ ) ve sosyal fizik kaygısının (sırasıyla 29.0 \pm 9.9 ve $23.1 \pm 9.3$ ) risk altındaki bireylerde anlamlı olarak daha yüksek olduğu bulunmuştur $(p<0.05)$. Yeme davranış bozukluğu riski altında olan öğrenciler arasında sigara ve alkol kullanma durumu ise sirasiyla $\% 27.0$ ve $\% 25.9$ olarak saptanmıştır (Tablo 5).

\section{TARTIŞMA}

Dünya genelinde üniversite öğrencileri arasında yeme bozuklukları yaygındır (26). Üniversite öğrencileri yaşam tarzı ve beslenme alışkanlıklarındaki hızlı değişim, sosyal çevre ve ekonomik durum, akran baskısı, akademik stres, arkadaş ilişkileri gibi yeme bozuklukları riskini arttıran çeşitli faktörlere sahiptir $(27,28)$. Yapılan bu çalışmada Gümüşhane Üniversitesi Sağlık Bilimleri Fakültesi'nde eğitim görmekte olan öğrenciler arasında yeme davranışı bozukluğu riski REZZY'e göre \%28.6 olarak bulunmuş olup, kız öğrencilerde yeme davranış bozukluğunun hem ortalama puanı hem de sıklığının erkeklerden 
Tablo 5. REZZY’e göre yeme davranış bozukluğu olan ve olmayan öğrencilerin bazı özelliklerinin karşılaştırılması

\begin{tabular}{|c|c|c|c|}
\hline & $\begin{array}{c}\text { REZZY } \leq 1 \\
(n=227)\end{array}$ & $\begin{array}{c}\text { REZZY } \geq 2 \\
(n=91)\end{array}$ & p§ \\
\hline & $\overline{\mathrm{X}} \pm \mathbf{S S}$ & $\overline{\mathrm{X}} \pm \mathrm{SS}$ & \\
\hline BKI $\left(\mathrm{kg} / \mathrm{m}^{2}\right)$ & $21.4 \pm 2.9$ & $22.8 \pm 2.9$ & $0.000^{*}$ \\
\hline BECK toplam puanı & $11.5 \pm 8.7$ & $14.4 \pm 9.0$ & $0.010^{*}$ \\
\hline SFKÖ toplam puanı & $23.1 \pm 9.3$ & $29.0 \pm 9.9$ & $0.000^{*}$ \\
\hline \multicolumn{4}{|l|}{ SFKÖ alt boyutları } \\
\hline ODB & $14.0 \pm 6.7$ & $16.9 \pm 6.8$ & $0.001 *$ \\
\hline FGR & $9.1 \pm 4.2$ & $12.0 \pm 4.7$ & $0.000^{*}$ \\
\hline Sigara kullanma durumu & $\mathrm{S}(\%)$ & $\mathrm{S}(\%)$ & pII \\
\hline Evet & $54(73.0)$ & $20(27.0)$ & \multirow{2}{*}{0.426} \\
\hline Hayır & $173(70.9)$ & $71(29.1)$ & \\
\hline \multicolumn{4}{|l|}{ Alkol kullanma durumu } \\
\hline Evet & $20(74.1)$ & 7 (25.9) & \multirow{2}{*}{0.471} \\
\hline Hayır & $207(71.1)$ & $84(28.9)$ & \\
\hline
\end{tabular}

anlamlı olarak fazla olduğu görülmüştür. Daha önce yapılan çalışmalarda da benzer sonuçlar elde edilmiştir (16,29). Bu durumun, kadınların erkeklere göre vücut şekli, vücut ağırlığı ve diyet yapma ile daha fazla meşgul olmalarından kaynaklandığı düşünülmektedir (30,31). Üniversite öğrencileri yeme davranış bozukluğu açısından risk altında olduğundan, gelişebilecek olası bir yeme bozukluğuna karşı öğrencilerin bilinçlendirilmesi ve özellikle risk altında olan öğrencilerin (kız öğrenciler, hafif şişmanlık ve/veya obezite varlığı, depresyon varlığı vb.) incelenerek tedavi için erken dönemde bir uzmana yönlendirilmesi faydalı olacaktır.

Depresyon dünya genelinde görülen en önemli mental bozukluk olup, üniversite öğrencileri depresyon açısından yüksek risk altındadır (32). Bu çalışmada yaklaşık her 4 üniversite öğrencisinden birinin depresyon belirtileri gösterdiği saptanmıştır. Depresyon prevalansını inceleyen 195 çalışmanın ele alındığı 129,123 kişiyi kapsayan ve 47 ülkede yapılan çalışmaların derlendiği bir meta-analizde, bu çalışma sonuçları ile benzer olarak depresyon ve depresif belirtiler gösteren öğrencilerin prevalansının \%27.2 olduğu bulunmuştur (33). Liseden üniversiteye geçen genç yetişkinler bu dönemde ekonomik ve sosyal olarak çeşitli sorunlarla karşılaştıkları, yeni ortama uyum sağlamaya çalıştıkları için büyük bir baskı ve stres yaşayabilirler. Bu dönemde yaşanılan stres, depresyonun ortaya çıkmasında önemli bir rol oynayabilir.

Beslenmede yaşanan geçişlerle birlikte özellikle gelişmekte olan ülkelerde, dünya genelinde oldukça yaygın olan hafif şişmanlık ve obezite görülme sıklığı gittikçe artmaktadır (34). Hafif şişmanlık ve obezite prevalansı cinsiyete göre farklılık gösterebilmektedir $(35,36)$. Bu çalışmada da erkek öğrencilerin \%18.2'si, kızların ise \%11.4'ü hafif şişman ve obez olduğu saptanmıştır. Üniversite dönemi yeni çevrelerine uyum sağlamaya çalışan genç yetişkinler için bir geçiş dönemi olduğundan, bu dönemde birçok üniversite öğrencisinin vücut ağırlığı artmaktadır (37). Bu yönden bakıldığında üniversite öğrencilerinin hafif şişmanlık ve obezite sorununa daha fazla dikkat çekilmesi gerektiği söylenebilir.

Yeme davranış bozukluğu mental bozukluğa sahip bireyler arasında oldukça yaygın olarak 
gözlenmektedir (38). Ayrıca depresyon yeme davranış bozukluğu olan obez bireylerde de yaygın olarak karşılaşılan bir sorundur (39). Bu çalışmada yeme davranış bozukluğu riski altında olan bireylerin Beck depresyon skorları ve BKI'leri anlamlı olarak daha fazladır. Benzer olarak, Vardar ve Erzengin de (40), lise öğrencileri üzerinde yaptıkları bir çalışmada yeme bozukluğu tanısı alan olguların \%13.2'sine majör depresyonun eşlik ettiğini, BKİlerinin de daha fazla olduğunu bulmuştur. Ayrıca yapılan çalışmalarda, yeme bozukluğu kriterlerini karşılayan kişilerin obez olma ihtimalinin de daha yüksek olduğu $(38,41)$ ve yeme bozukluğu riski altında olan öğrencilerin orta ve şiddetli düzeyde depresyona maruz kaldıkları bulunmuştur (16). Sonuç olarak, depresyon ve obezitenin yeme davranış bozuklukları için itici bir güç olduğu söylenebilir. Bu nedenle yeme davranış bozukluğu riski altında olan bireyler hem depresyon hem de obezite açısından değerlendirilmelidir.

Sosyal fizik kaygısı, bireyin başkalarına nasıl göründüğü konusunda yaşadığı kaygıdır. Vücut algısıyla ilgili yaşanan bozukluk, kadın cinsiyeti, obezite ve yaş (ergenlik veya orta yaşta daha sık) sosyal fizik kaygısını arttıran en önemli risk faktörleridir (11). Bu çalışmada da kız öğrencilerin sosyal fizik kaygılarının erkeklere göre daha yüksek olduğu bulunmuştur. Bu sonuç benzer çalışmalarda da desteklenmiştir $(42,43)$. Ayrıca hafif şişman ve obez olan kız öğrencilerin sosyal fizik kaygı puanları genel kız öğrenci popülasyonuna göre daha yüksek olarak saptanmış, ancak erkek öğrencilerde bu sonuç anlamlı bulunmamıştır. Literatürde, özellikle kadın ağırlıklı popülasyonlarda obez bireylerin, obez olmayanlara göre fiziksel görünümlerinden daha az hoşnut oldukları ve sosyal görünüş kaygılarının daha yüksek olduğu bulunmuştur $(11,44,45)$. Kızların erkeklere göre sosyal fizik kaygı ölçeğinden aldıkları puanların daha yüksek olması, yaştan bağımsız olarak vücutlarının nasıl göründüğüyle daha fazla ilgilenmelerinden kaynaklandığı düşünülmektedir (30). Sonuç olarak, sosyal fizik kaygısının kızlar arasında daha yaygın olduğu ve obeziteyle pozitif olarak ilişkili olduğu söylenebilir.
Sosyal fizik kaygısı beden memnuniyetsizliğini, vücut ağırlığı ve şekliyle ilgili kaygıları, yeme davranış bozukluklarını, depresyonu tetikleyen ve diyet davranışlarını önemli ölçüde etkileyen bir sorundur (11). Bu çalışmada da yeme davranış bozukluğu riski altında olan bireylerin sosyal fizik kaygısı ölçeğinden ve alt boyutlarından alınan puanların, risk altında olmayan bireylere göre daha yüksek olduğu saptanmıştır $(\mathrm{p}<0.05)$. Benzer olarak yapılan çalışmalarda da yeme davranış bozukluğunun beden memnuniyetsizliğiyle ve sosyal fizik kaygısıyla pozitif yönde ilişkili olduğu gösterilmiştir (46-48). Beden imgesinden rahatsız olma, vücut ağırlığının yanlış algılanması gibi durumlarda ortaya çıkabilecek yanlış yeme davranışları açısından üniversite öğrencileri dikkatle incelenmelidir.

Bu çalışma, Gümüşhane Üniversitesi Sağlık Bilimleri Fakültesi öğrencileri üzerinde yapılmış olup, tüm üniversite öğrencilerine genellenemez. Bununla birlikte, kesin tanı olmaksızın yeme davranış bozukluğu ve depresyon riski, katılımcıların beyanıyla ölçeklerden alınan puanlara göre değerlendirilmiştir. Rastgele örnekleme yönteminin kullanıldığı bu çalışmada evrenin kız ve erkek oranının eşit olmaması nedeniyle mevcut örneklemdeki cinsiyet dağılımı dengesiz olmuştur. Ayrıca bu çalışmada Beslenme ve Diyetetik Bölümü öğrencileri de çalışmaya dahil edilmiş olup, bu bölümdeki öğrencilerin diğer bölümlere göre yeme davranışı konusundaki bilgi ve farkındalıklarının ölçeklere verdikleri cevapları da etkileyebilmesi çalışmanın sınırlı yönlerinden bir diğeridir. Yeme davranış bozukluklarının tespitinde birden fazla ölçekten yararlanılmış olması ile örneklem sayısının \%95 güven aralığıyla tespit edilmiş olması çalışmanın güçlü yönleridir.

$\mathrm{Bu}$ çalışma, mevcut literatürden farklı olarak yeme bozuklukları risk faktörlerinden cinsiyet, BKİ, sosyal fizik kaygisı ve depresyon durumunu hem bir arada ele alarak hem de farklı ölçekler kullanarak irdelemiştir. Çalışmada BKİ, sosyal fizik kaygısı ve depresyon düzeyinin öğrencilerin yeme davranışlarını etkilediği ve bu durumun ileride gelişebilecek olası bir yeme bozukluğu riski açısından göz önünde bulundurulması 
gerektiği ulaşılan önemli sonuçlar arasındadır. $\mathrm{Bu}$ sonuçlardan yola çıkılarak, üniversite öğrencilerinin sosyal fizik kaygı ve depresyon düzeylerini azaltmak amacıyla çalışmalar yapılmalı, vücut ağırlığı denetimi konusunda öğrenciler bilgilendirilmelidir.

Çıkar çatışması - Conflict of interest: Yazarlar çıkar çatışması olmadığını beyan ederler. - The authors declare that they have no conflict of interest.

\section{KAYNAKLAR}

1. Bundros J, Clifford D, Silliman K, Neyman Morris M. Prevalence of Orthorexia nervosa among college students based on Bratman's test and associated tendencies. Appetite. 2016;101(3):86-94.

2. Vaquero-Cristobal R, Alacid F, Muyor JM, LopezMinarro PA. Body image; literature review. Nutr Hosp. 2013;28(1):27-35.

3. Parker SC, Lyons J, Bonner J. Eating disorders in graduate students: exploring the SCOFF questionnaire as a simple screening tool. J Am Coll Health. 2005;54(2):103-7.

4. Culbert KM, Racine SE, Klump KL. Research Review: What we have learned about the causes of eating disorders - a synthesis of sociocultural, psychological, and biological research. J Child Psychol Psychiatry. 2015;56(11):1141-64.

5. Anschutz DJ, Engels RC, Van Strien T. Susceptibility for thin ideal media and eating styles. Body Image. 2008;5(1):70-9.

6. Baysal A. Beden Ağırlığı Denetimi. Baysal A, Aksoy M, Besler T, Bozkurt N, Keçecioğlu S, Merdol T, ve ark., Editörler. Diyet El Kitabi. 5. Baskı. Ankara: Hatipoğlu Yayınları; 2008. s.39-66.

7. Kessler RC, Berglund PA, Chiu WT, Deitz AC, Hudson JI, Shahly V, et al. The prevalence and correlates of binge eating disorder in the World Health Organization World Mental Health Surveys. Biol Psychiatry. 2013;73(9):90414.

8. Hunt J, Eisenberg D. Mental health problems and helpseeking behavior among college students. J Adolesc Health. 2010;46(1):3-10.

9. İkiz F, Otlu Ö. Üniversite yaşamına uyum sürecinde yaşanan sorunlar ve başa çıkma yolları. CBÜ Sosyal Bilimler Dergisi. 2015;13(4):36-52.

10. Hamarta E. Ergenlerin sosyal kaygılarının kişiler arası problem çözme ve mükemmeliyetçilik açısından incelenmesi. İlköğretim Online. 2009;8(3):729-40.

11. Sanlier N, Pehlivan M, Sabuncular G, Bakan S, Isguzar Y. Determining the relationship between body mass index, healthy lifestyle behaviors and social appearance anxiety. Ecol Food Nutr. 2018;57(2):124-39.

12. Linardon J, Braithwaite R, Cousins R, Brennan L. Appearance-based rejection sensitivity as a mediator of the relationship between symptoms of social anxiety and disordered eating cognitions and behaviors. Eat Behav. 2017;27:27-32.

13. Doğan T. Sosyal Görünüş Kaygısı Ölçeği’nin (SGKÖ) Türkçe uyarlaması: geçerlik ve güvenirlik çalışması. H. U. Eğitim Fakültesi Dergisi. 2010;39(39):151-9.

14. Storrie K, Ahern K, Tuckett A. A systematic review: students with mental health problems - a growing problem. Int J Nurs Pract. 2010;16(1):1-6.

15. Field AE, Sonneville KR, Micali N, Crosby RD, Swanson SA, Laird NM, et al. Prospective association of common eating disorders and adverse outcomes. Pediatrics. 2012;130(2):289-95.

16. Tavolacci MP, Grigioni S, Richard L, Meyrignac G, Déchelotte P, Ladner J. Eating disorders and associated health risks among university students. J Nutr Educ Behav. 2015;47(5):412-20.

17. Garner DM, Garfinkel PE. The Eating Attitudes Test: An index of the symptoms of anorexia nervosa. Psychol Med. 1979; 9(2):273-9.

18. Savaşır I, Erol N. Eating Attitude test: anorexia nervosa symptoms index. Turk Psikiyatri Derg. 1989;7(23):19-25.

19. Hart EA, Leary MR, Rejeski WJ. The measurement of social physique anxiety. J Sport Exerc Psychol. 1989;(11):94-104.

20. Mülazımoğlu Ballı Ö, Aşçı F. Sosyal fiziksel kaygı envanterinin geçerlik ve güvenirlik çalışması. Spor Bilimleri Dergisi. 2006;17(1):11-9.

21. Beck AT, Ward C, Mendelson M. Beck Depression Inventory (BDI). Arch Gen Psychiatry. 1961;(4):561-71.

22. Hisli N. Beck Depresyon Envanterinin üniversite öğrencileri için geçerliği, güvenirliği. Psikoloji Dergisi. 1989;7(23):3-13.

23. Hill LS, Reid F, Morgan JF, Lacey JH. SCOFF, the development of an eating disorder screening questionnaire. Int J Eat Disord. 2010;43(4):344-51.

24. Aydemir Ö, Köksal B, Sapmaz \$̧Y, Yüceyar H. Kadın üniversite öğrencilerinde REZZY yeme bozuklukları ölçeği Türkçe formunun güvenilirlik ve geçerliliği. Anadolu Psikiyatri Derg. 2015;16(1):31-5.

25. Hautala L, Junnila J, Alin J, Grönroos M, Maunula A-M, Karukivi M, et al. Uncovering hidden eating disorders using the SCOFF questionnaire: cross-sectional survey of adolescents and comparison with nurse assessments. Int J Nurs Stud. 2009;46(11):1439-7.

26. Yager Z, O’Dea JA. Prevention programs for body image and eating disorders on university campuses: a review 
of large, controlled interventions. Health Promot Int. 2008;23(2):173-89.

27. Musaiger AO, Al-Mannai M, Tayyem R. Risk of disordered eating attitudes among adolescents in seven Arab countries by gender and obesity: a cross-cultural study. Appetite. 2013;60(1):162-7.

28. Frankos KC, Frangos CC. Assessing eating disorder risk: the pivotal role of achievement anxiety, depression and female gender in non-clinical samples. Nutrients. 2013;5(3):811-28.

29. Schulte SJ. Predictors of binge eating in male and female youths in the United Arab Emirates. Appetite. 2016;105:312-9.

30. Radmanovic-Burgic M, Gavric Z, Burgic S. Eating attitudes in adolescent girls. Psychiatr Danub. 2011;23(1):64-8.

31. Calzo JP, Sonneville KR, Haines J, Blood EA, Field AE, Austin SB. The development of associations among body mass index, body dissatisfaction, and weight and shape concern in adolescent boys and girls. J Adolesc Health. 2012;51(5):517-23.

32. Lei XY, Xiao LM, Liu YN, Li YM. Prevalence of depression among Chinese university students: a meta-analysis. PLoS One. 2016;11(4):e0153454.

33. Rotenstein LS, Ramos MA, Torre M, Segal JB, Peluso MJ, Guille C, et al. Prevalence of depression, depressive symptoms and suicidal ideation among medical students: a systematic review and meta-analysis. JAMA. 2016;316(21):2214-36.

34. Ren X, Chen Y, He L, Jin Y, Tian L, Lu M, et al. Prevalence of underweight, overweight and obesity in university students from the region of Anhui (China). Nutr Hosp. 2014;31(3):1089-93.

35. Jiang S, Peng S, Yang T, Cottrell R, Li L. Overweight and obesity among chinese college students: an exploration of gender as related to external environmental influences. Am J Mens Health. 2018;12(4):926-34.

36. Cluskey M, Grobe D. College weight gain and behavior transitions: male and female differences. J Am Diet Assoc. 2009;109(2):325-9.

37. Pliner P, Saunders T. Vulnerability to freshman weight gain as a function of dietary restraint and residence. Physiol Behav. 2008;93(1-2):76-82.

38. Woldeyohannes HO, Soczynska JK, Maruschak NA, Syeda $\mathrm{K}$, Wium-Andersen IK, Lee Y, et al. Binge eating in adults with mood disorders: Results from the International Mood Disorders Collaborative Project. Obes Res Clin Pract. 2016;10(5):531-43.

39. Faulconbridge LF, Wadden TA, Thomas JG, JonesCorneille LR, Sarwer DB, Fabricatore AN. Changes in depression and quality of life in obese individuals with binge eating disorder: bariatric surgery versus lifestyle modification. Surg Obes Relat Dis. 2013;9(5):790-6.
40. Vardar E, Erzengin M. Ergenlerde yeme bozukluklarının yaygınlığı ve psikiyatrik eş tanıları iki aşamalı toplum merkezli bir çalışma. Turk Psikiyatri Derg. 2011;22(4):205-12.

41. Duncan AE, Ziobrowski HN, Nicol G. the prevalence of past 12-month and lifetime DSM-IV eating disorders by BMI Category in US Men and Women. Eur Eat Disord Rev. 2017;25(3):165-71.

42. Ballı ÖM, Erturan-İlker G, Arslan Y. Achievement goals in Turkish high school PE setting: The predicting role of social physique anxiety. Int J Educ Res. 2014;67:30-9.

43. Hagger MS, Stevenson A. Social physique anxiety and physical self-esteem: gender and age effects. Psychol Health. 2010;25(1):89-100.

44. Titchener K, Wong QJJ. A weighty issue: Explaining the association between body mass index and appearancebased social anxiety. Eat Behav. 2015;16:13-6.

45. Crocker PR, Sabiston CM, Kowalski KC, McDonough MH, Kowalski N. Longitudinal assessment of the relationship between physical self-concept and health-related behavior and emotion in adolescent girls. J Appl Sport Psychol. 2006;18(3):185-200.

46. Morales A, Gomes A, Jimenez B, Jimenez F, Leon G, Majano A, et al. Binge eating disorder: prevalence, associated factors and obesity in university students. Rev Colomb Psiquiatr. 2015;44(3):177-82.

47. Coker E, Abraham S. Body weight dissatisfaction: a comparison of women with and without eating disorders. Eat Behav. 2014;44(3):453-459.

48. Lanfranchi MC, Maiano C, Morin AJS, Therme P. Social physique anxiety and disturbed eating attitudes and behaviors in adolescents: Moderating effects of sport, sport-related characteristics, and gender. Int J Behav Med. 2015;22(1):149-60. 